\title{
E-management Educational System based on Mobile Cloud Computing
}

\author{
Hanan Rezk, PhD \\ Faculty of Specific Education, \\ Mansoura University \\ Mansoura, Egypt
}

\author{
Ahmed E. Amin,PhD \\ Faculty of Specific Education, \\ Mansoura University \\ Mansoura, Egypt
}

\author{
Maha D. Elmorshdy \\ Dept. of Technology \\ Development \\ Mansoura, Egypt
}

\begin{abstract}
This study aims mainly to build an android based program to manage educational institutions using mobile cloud computing. Therefore, overcoming traditional learning problems and utilizing mobile technology owned by students and teaching staff. This paper provides a vision to build an android-based program to manage educational institutions using cloud computing technique to solve interaction problems and develop communication skills between the two ends of the learning process, and measure the effectiveness of this program on the learning environment.

The system has been tested and a questionnaire was applied to measure user satisfaction with the proposed program. A research sample of 30 ( 24 students - 6 instructors). In order to measure the reliability of the study tools, the researcher used the Alpha Kronbach Laboratory to verify the stability of the study tools. The table shows that the coefficient of general reliability is a high reliable percentage that we can depend on when applying the study. The frequencies and the arithmetic mean were calculated for each category of questionnaire and using a Spearman rank-order correlation was performed to determine whether significant associations exist between the variables being examined. The statistical results shows general satisfaction with the program, increases the communication rates between students and instructors with the privacy of each user and provides the information he needs any time and everywhere.
\end{abstract}

\section{Keywords}

Cloud Computing, Educational System

\section{INTRODUCTION}

Mobile cloud computing is the transfer of infrastructure where all data is stored and processed outside the mobile device. Cloud computing transfers and stores data from mobile to the cloud, helping users access not only mobile users but also all smart phone users.

All investors have been attracted to MCC because it reduces the development and implementation costs of mobile applications. So it allows users to acquire the

One of the most important issues proposed for discussion is the design of mobility management techniques. In our research, we focus on the methods used to manage and support cloud computing systems. Finding your device's current location is useful for determining whether it can move from or towards the active mobile cloud.

In this paper The researcher found that the tasks carried out by the program are divided into two parts. The first is for the students and the second part is for professors. One of the most important tasks for both students and professors are: View the academic and personal profile, Accessing to the chat rooms, View the college news page, Presenting the subjects for both the student and professor, and Enable the professors to make a quiz for the students or delete a previous one and enable the student to answer the quiz.

The paper is organized as follows: section 2presents the literatures review, section 3 presents the proposed framework, section 4 presents applications and results, and section 5 presents conclusions.

\section{LITERATURES REVIEW}

Ibrahim Faraj Abdulaziz (2016) has Designed a System Based on Cloud Computing and E-Management Standards for Developing E-Tasks Performance of Mansoura University Faculty and their Attitudes Toward it. After discussing that the university is the basis of human thought and sources of investment for the country and the development of wealth. Such fact necessitates fulfilling various requirements to guarantee its progress and to upgrade its services. Therefore, administrations of universities have recently adopted various and numerous mechanisms to achieve its goals as well as those of community. Electronic management and cloud computing are two of the latest mechanisms of regulating and improving the performance of university administration as it constitutes a comprehensive and integrative input to perform a highly qualified and distinct work.

Marcelo A.Marotta, Leonardo R.Faganello and Matias A.Klafke Schimuneck (2015) The researchers applied mobile cloud computing to large numbers of devices to be able to control cloud computing systems. They have configured the infrastructure for mobile cloud computing and have enabled end users and officials to provide feedback and provide a survey of their experiences and opinions. In addition, End users can implement quality standards for the system, which enables the discovery of errors in the MCC environment. The researchers have set up a first model in which supervisors collaborate with users in managing, designing and analyzing MCC performance

This research aims to be an initial step to introduce a management system for MCC environments. Automated learning techniques can be used to manage systems, control their requirements and determine the basic structure of an MCC environment.

Jos_e A. Gonzalez-Martínez , Miguel L. Bote-Lorenzo, Eduardo G_omez-S_anchez and Rafael Cano-Parra (2014) Researchers have compiled studies related to the use of cloud computing in education and have found that this technique gives advantages and adds benefits to education. They also noted that the application of cloud computing has many benefits for the enterprise as well as its employees. They have introduced several ways to save cost, create the right environment and infrastructure specifications to adopt a cloud-based system. They also proposed several methods to 
facilitate scalability and availability affordances. As for the information staff, they propose to replicate the repetitive tasks so that they can focus on the main tasks.

Marwa Ayad Mohamed (2015) The researcher identified MCC as one of the most widespread and although it faces many challenges like battery life, limited bandwidth, low power computing and storage space, it is still in rapid increase in mobile usage and also for its applications. This problem was solved by transferring computing power and high storage space to the cloud. MCC has developed and diversified its applications, for example the face recognition program used as a crime control tool. This program requires huge storage space and high computing power.

Minjuan Wang, Yong Chen, and M. Khan (2012) They talked about the difficulties that MCC faces and that the following disadvantages must be fixed such as the high price of the mobile device, the possibility of providing an Internet connection, low network transfer rate, and the resources allocated for education are usually limited. Combined with the advantages of mobile learning and cloud computing, this technology addresses the aforementioned flaws. On the other hand, students and teachers must deal with risks such as loss of control of applications and damage to security and privacy, but teachers and students gain many advantages when using the cloud, it gives students freedom, ease of use, availability and diverse learning methods.

N.Mallikharjuna, V.Sathyendra, and C. Sasidhar (2012) They conclude their paper saying cloud computing has the potential to change educational systems and give way to development and expansion dramatically. As e-learning is currently receiving a lot of publicity, this will help cloud computing to spread. Cloud computing helps to develop and increase quality education for the poor. Cloud-based education will help students, employees, teachers and institutions reach as wide a range as possible. A poor student from parts of the village will have access to the knowledge provided by a professor in a remote location of the world. It will soon happen that all colleges and schools will support the system all over the world.

\section{THE PROPOSED PROGRAM FRAMEWORK}

We will display the five modules of the system. Those modules are: profile module, educational module, exams module, chatting module, and news module as shown in figure 1

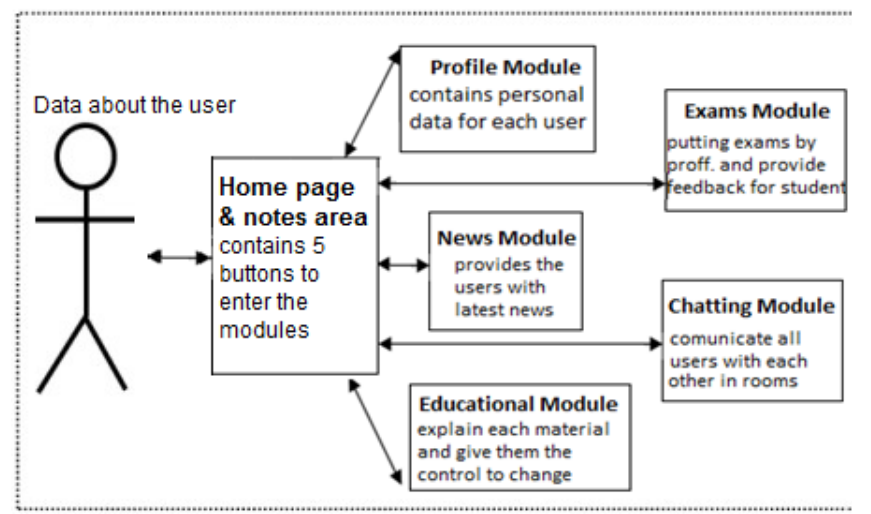

\subsection{Educational Module}

The educational module presents the educational resources. It Contains scientific materials. This list of material is automatically loaded according to the student academic year or according to professor's name. when they click on, there is an opening page for every material. The teaching lessons consist of files they can be downloaded by clicking on them. They can also upload files or images for each material. This module helps students and teachers to exchange resources easily, To facilitate the educational process.

\subsection{Profile Module}

The profile module works on saving user's personal information and the studying information also such as exam and lecture schedules. Also, the Academic data such as grades and payment of expenses. It therefore provides users with data validation and saves search efforts.

\subsection{Exams Module}

First part for students, The exams module consists of tests for students. Through which the test can be passed with feedback given at the end of each question and at the end of the test. The second part is for preparing tests for professors. Each teacher has the right to put a test for the material he is teaching and can cancel the test or modify it through a special code makes it difficult to modify or delete his tests. Only the teacher can do that. The importance of this module Stems from passing the tests and the placement is very easy and from any place.

\subsection{Chatting Module}

The chatting module consists of two windows the first one consists of a list having chatting rooms. When the user clicks on one of the rooms, it opens the second window and he can start chatting. The importance of this module is the real and rapid communication between users to answer the academic questions.

\subsection{News Module}

In this module, there's a list of the latest news of the college and its scientific sections. It helps to communicate with the college and know all the things happening inside.

\section{EXPERIMENTAL WORK 4.1 Programming Tools}

The mobile program is designed and developed by android studio 2.2.3, and we developed the web pages on the server by php 5 using Notepad++ v5.9.8, and our database stored by MYSQL database using wamp server 64bits (x64) 3.0.6.

\subsection{Program Screens}

The opening screen of the program: It is the first screen of the system. The user selects the category, if he is a student or a professor and writes the username and his password on the textboxes then press the button LOGIN. As shown in figure 2, if he enters the right data he will enter the Main page As shown in figure 3. It is the most important page because it is the connector between the five modules. It is the same if he is a student or a professor, It has 7 buttons (Personal, News, Logout, Materials, Chatting, Exams and Add note part) we will explain the content of these buttons as following:

Fig. 1 The MCC program. 


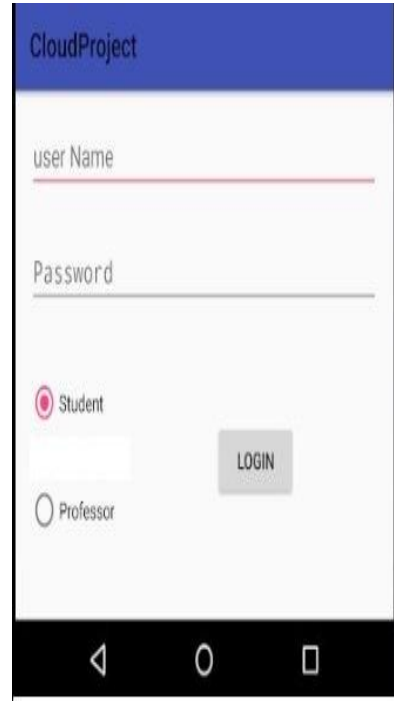

Fig. 2 The opening screen.

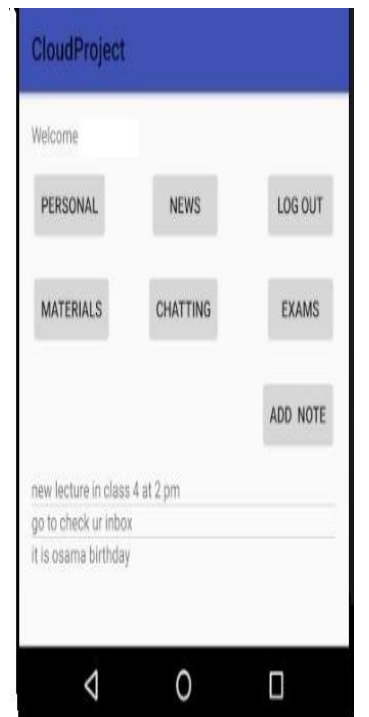

Fig. 3 the main page.

- "Personal": Takes you to your profile page and it is the entrance to the Profile Module. It works on saving user's personal information (name, address, phone... etc) and the studying information also such as the exam and lecture schedules. Also, the academic data such as grades and payment of expenses.

- "News": Takes you to college news and it is the entrance to news module. It is automatically loaded by the server every day.

- "Log out": Takes you out of the system.

- "Materials": It takes you to the user subjects and it is the entrance to Educational Module. It presents the educational resources. It Contains scientific materials as shown in figure 4. These lists of material names are automatically loaded according to the student academic year or according to the professor's name. When they click on it, it opens a page for every material. The teaching lessons consist of files which they can download by clicking on them. They can also upload files or images for each material. And only professors can delete files as shown in figure 5 .

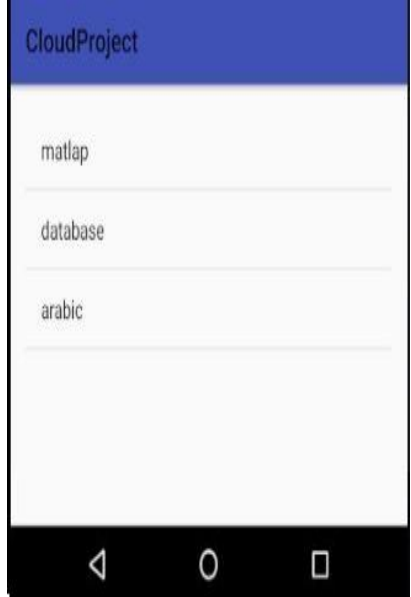

Fig. 4 The materials list.

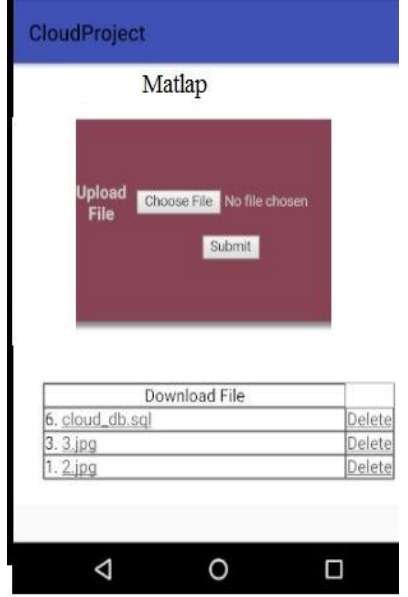

Fig. 5 Sample of materials page.
- "Chatting": Takes you to Chatting rooms and it is the entrance to the Chatting Module. The chatting module consists of two windows the first one consists of a list having chatting rooms as shown in figure 6. Only professors can add a new chatting room. when the user clicks on one of the rooms, it opens the second window and he can start chatting as shown in figure 7 .

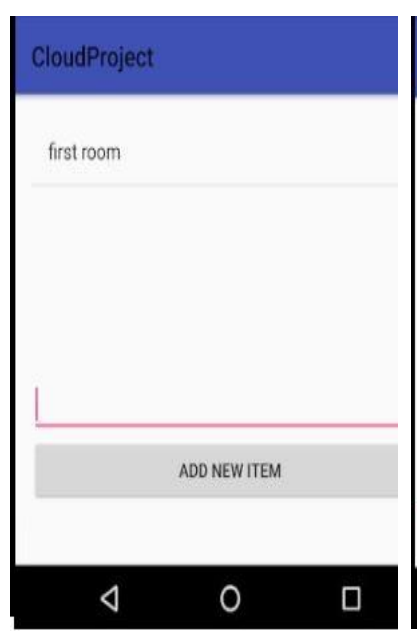

Fig. 6 Sample of chatting rooms list.

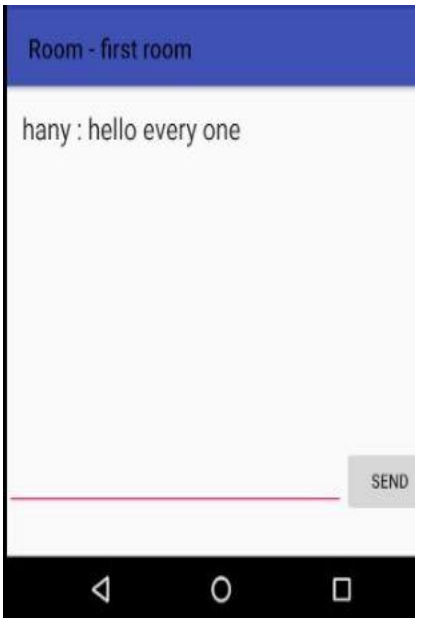

Fig. 7 Sample of conversation on chatting .
- "Exams": Takes you to the Exams section and it is the entrance to Exams Module. The exams module consists of quizzes for students as shown in figure 8 it is a sample of a question and its choices when the student click on the choice button it immediately gives feedback, if this answer is right or wrong. And in the end of the exam, it gives him the whole score as shown in figure 9. Preparing tests for professors as shown in figure 10, the professor can choose a class and a subject to make a new exam and then he must put a unique code for each exam to increase safety precautions. Then he can add questions and their answers then copy the right one so that the system can give the feedback as shown on figure 11 . 


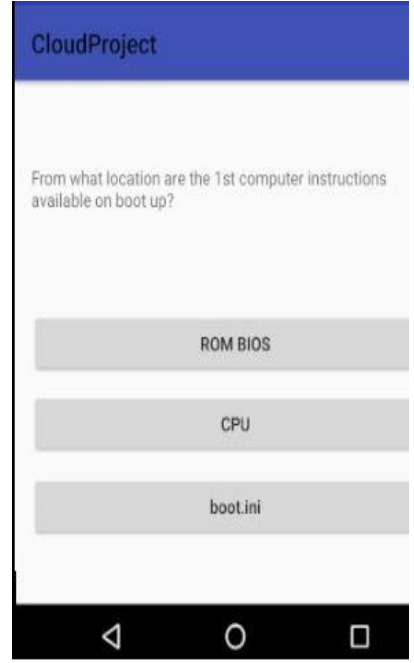

Fig.8 Sample of a question exam for students.

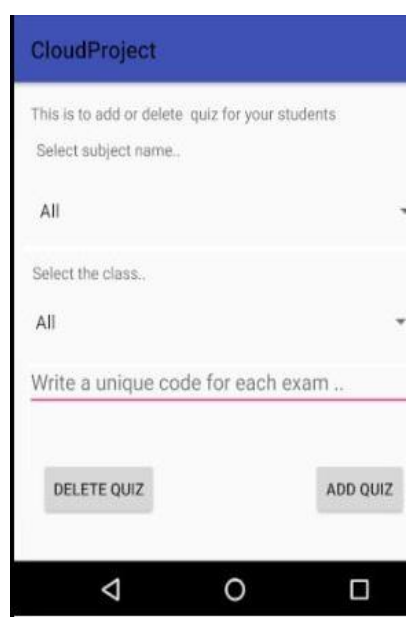

Fig.10 Sample of exam preparation by professors.

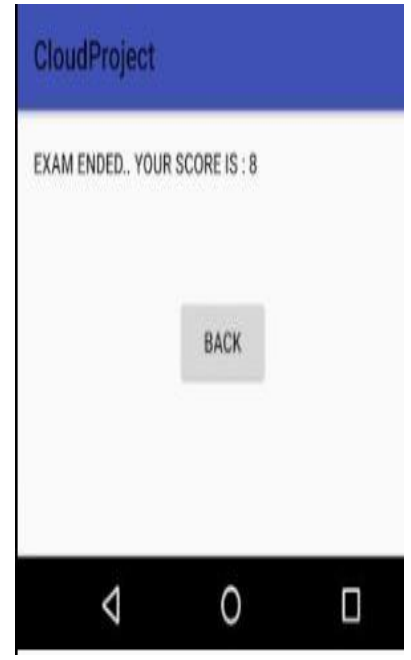

Fig. 9 exam score after the student answer.

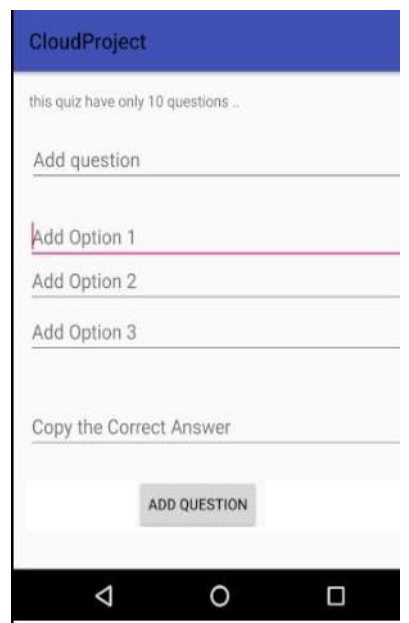

Fig.11 Sample of question in exam preparation by professors.

- "Add Note": This is to control the user notes. When it's pressed it, shows a message box that has the options of adding, deleting or modifying and it is listed above each other as shown on figure 2 . It is an optional feature which gives more privacy to the user. It helps him to organize his time and resources.

\section{RESULTS and DISCUSSION}

\subsection{Applying program}

After the design of the program and the testing of its modules, the files and database were uploaded to a server to be available to students and teachers. The software has been deployed and used by the sample.

\subsection{Sample}

The research sample was selected from 30 students of the second year diploma in the specialization of postgraduate studies at the faculty of Specific Education, Tanta University and 5 professors from the same faculty.

The system has been tested and a questionnaire was applied to measure user satisfaction with the proposed program. Sample search 30 (24 students - 6 instructors).

\subsection{Measurement tools}

The survey consisted of three scales: (1) Perceived Usefulness and Efficacy; (2) Perceived Ease of Use ; (3) Perceived academic interaction;

After searching for evaluation tools for the questionnaire, the researcher used the Alpha Cronbach Laboratory to measure the range of Reliability by using this definition; it is implicitly assumed that the average correlation of a set of items is an accurate rating of the average correlation of all items that relates to a certain construct. The standardized Cronbach's alpha can be defined as shown:

$$
\alpha \text { standardized }=\frac{K r}{(1+(K-1) r)}
$$

where $\{\mathrm{K}\}$ is as above and $\{\mathrm{r}\}$ the mean of the $\{\mathrm{K}(\mathrm{K}-$ 1)/2\} non-redundant correlation coefficients (i.e., the mean of an upper triangular, or lower triangular, correlation matrix). If the result is greater than 0.7 , the test or questionnaire will be reliable.

Then the researcher uses The Spearman's rank-order correlation and it is defined as the nonparametric version of the Pearson product moment correlation. Spearman's correlation coefficient ( $\rho$, also is signified by rs) measures the strength and direction of association between two or more ranked variables. it can be computed by using the popular formula:

$$
r_{s}=1-\frac{6 \sum d_{i}^{2}}{n\left(n^{2}-1\right)}
$$

Where $d_{i}=r g\left(X_{i}\right)-r g\left(Y_{i}\right)$ is the difference between the two ranks of each observation and $\{n\}$ is the number of observations

Correlation is an effect size and so we can verbally describe the strength of the correlation using the following guide for the absolute value of :

- $\quad .00-.19$ 'very weak'

- $.20-.39$ 'weak'

- $\quad .40-.59$ 'moderate'

- $\quad .60-.79$ 'strong'

- $\quad .80-1.0$ 'very strong'

The tools used for measuring the constructs are developed by utilizing items from previously validated scales so that they are more suitable for the cloud computing applications, and The descriptive statistics were reviewed using SPSS v22.

The validity of the study procedures is handled by two faculty professors with a review of elements and measurements and the addition of field experience.

\subsection{Statistics and Results}

First of all the researcher got the type of the program users and he got that $80 \%$ are students and $20 \%$ instructors. As shown in figure 12 . 


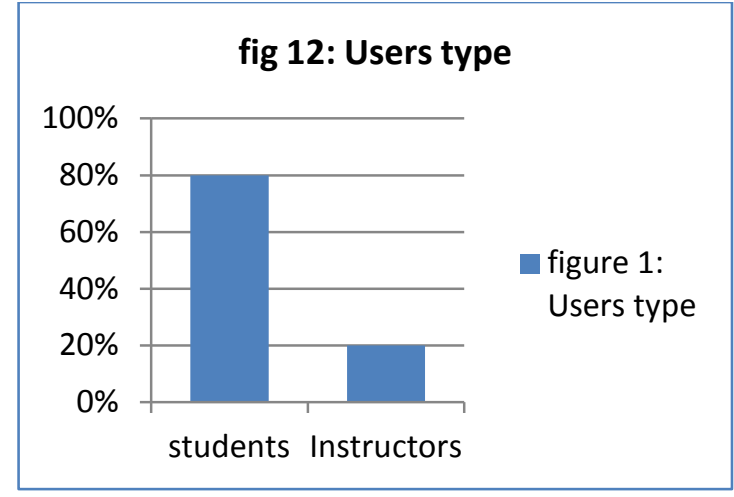

Then he asked the users who are the most interacting users while using the program, and the results appeared that $73.3 \%$ for students, $20 \%$ for all and $6.7 \%$ for instructors. As shown in figure 13.

\section{fig 13: The most inteacting users}

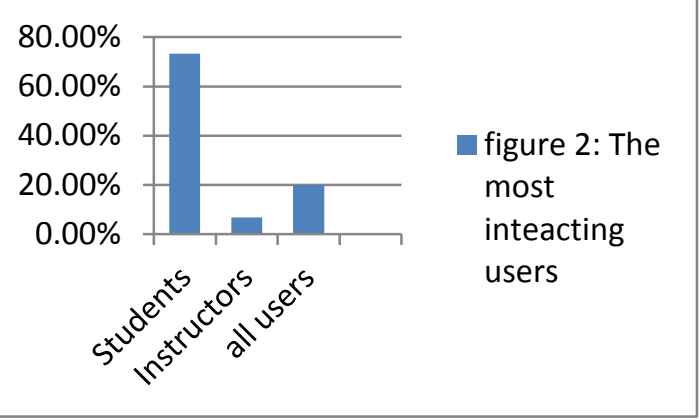

Also the frequencies and the arithmetic mean were calculated for each category of questionnaire and The statistical results showed general satisfaction with the program, And increase the communication rates between students and instructors such as:-

- $90 \%$ is Satisfied with the communication between users within the program.

- $\quad 80 \%$ the program has provided help to resolve their problems.

- $\quad 86 \%$ thinks the program is easy to use and simple.

- $\quad 85 \%$ the program helps them to memorize materials and academic achievement.

- $90 \%$ is generally satisfied with their use of the program and recommends it.

In order to measure the reliability of the study tools, the researcher used the Alpha Cronbach Laboratory to verify the stability of the study tools. The table shows that the coefficient of reliability is a high reliable percentage for the three scales and in general because the result is greater than 0.7 that we can depend on applying the study.
Table 1:Reliability Statistics

\begin{tabular}{|c|c|c|}
\hline Variables & $\begin{array}{c}\text { Cronbach's } \\
\text { Alpha }\end{array}$ & N of Items \\
\hline $\begin{array}{c}\text { Perceived Useful- } \\
\text { ness and Efficacy }\end{array}$ & 0.801 & 7 \\
\hline $\begin{array}{c}\text { Perceived Ease of } \\
\text { Use }\end{array}$ & 0.821 & 7 \\
\hline $\begin{array}{c}\text { Perceived } \\
\text { academic } \\
\text { interaction }\end{array}$ & 0.796 & 18 \\
\hline General & 0.811 & \\
\hline
\end{tabular}

Correlation analysis using a Spearman rank order correlation was performed to determine whether significant associations exist between the variables being examined. A very strong and significant relationship between the Usefulness and Efficacy scale and Ease of Use scale $(\mathrm{rs}(30)=0.849)$ because it is between (.80-1.0) allows the rejection of the null for $\mathrm{H} 1$. There was also a moderate positive association between Ease of Use scale and academic interaction scale $(\mathrm{rs}(30)=0.492)$ because it is between (.40-.59) allows the rejection of the null for $\mathrm{H} 1$. And also a moderate positive association between Usefulness and Efficacy scale and academic interaction scale $(\mathrm{rs}(30)=0.523)$ also allows the rejection of the null for $\mathrm{H} 1$.

\subsection{Discussion}

The main goal of this research was to examine if the introducing Mobile cloud computing into the educational system will benefit the educational process or not. While we acknowledge that this is only a preliminary study, The application of the proposed MCC program proved that the level of academic interaction increased significantly with the existence of specificity of the educational process. It appears remarkably in the previous paragraph, The Usefulness and Efficacy of the program within the educational process is strongly related to the ease of use of the program and its simple configuration. On this path we hope that future researchers in this field will identify the factors affecting the quality of education that lead to best practices to improve the success of the educational process.

This critical research has set the stage for the next direction of acceptance research, for overcoming traditional learning problems and utilizing mobile cloud technology owned by students and teaching staff.

\section{CONCLUSION}

Education is one of the most important and significant pillars of life for the development of the country so applying all available and possible technologies in this period will dramatically help. And one of the most important technologies is mobile cloud computing and E-management.. The study has proved that the application of these techniques helps significantly to increase communication and provide resources for students and teachers and other benefits more using mobile applications. The statistical results showed general satisfaction with the program. 


\section{REFERENCES}

[1] K. AbAziz, N. Azlina, A.M. Yusuf, A. Paul (2012). Potential for Providing Augmented Reality elements in special education via cloud computing. Faculty of Management, Faculty of Engineering and Technology, Multimedia University, Malaysia.

[2] N. Fernando, S. W. Loke, W. Rahayu (June 2012). Mobile cloud computing: A survey. Department of Computer Science and Computer Engineering, La Trobe University, Australia.

[3] H.F. El-Sofany, A. Al Tayeb, K. Alghatani , S. A. ElSeoud(Jan 2013). The Impact of Cloud Computing Technologies in E-learning. Arab East Colleges for Graduate Studies, Riyadh, Kingdom of Saudi Arabia.

[4] Masud. A. H, Huang. X (2012). An E-learning System Architecture based on Cloud Computing. World Academy of Science, Engineering and Technology.

[5] Mircea. M, Andreescu A.I. (2011). Using Cloud Computing in Higher Education: A Strategy to Improve Agility in the Current Financial Crisis .Academy of Economic Studies, Bucharest, Romania

[6] E MISEVI CIE, G BUDNIKAS (September 2011). Application of Cloud Computing at KTU:MS Live@Edu Case .Vilnius University.

[7] Douglas Rosette (July 2012) . The Impact of the Cloud on Higher Education.

[8] M. Z. Jafarlou, B. Arasteh, P. YousefzadehFard (2011) "A pattern-oriented and web-based architecture to support mobile learning software development", department of Computer, Tabriz Branch, Islamic Azad University, Tabriz, Iran.

[9] Katz, R (ed) (2009), The Tower and the Cloud: Higher Education in the Age of Cloud Computing, Educes, http://www.educause.edu/thetowerandthecloud

[10] Baker, J. (2009). Electronic management: time is money. Motor Equipment News ,p8-8.

[11] Hafez, I. A., \& Wahb, S. A. (2007). organization and administration Assets. Cairo University.

[12] Iulian, M. (2008). Implementing E-Management In Small And Medium Enterprises. Annals of the University of Oradea, Economic Science Series, 1409-1413.

[13] Mafraji, A. H. (2007). E-governance "intellectual foundations and the establishment of requirements process". The Arab Organization for Administrative Development.

[14] Mohammed, M. b. (2008). the possibility of application of electronic management in public administration education and education in the Holy Capital (Benin). Kingdom of Saudi Arabia: Umm Al-Qura University, College of Education, Department of Educational Administration and Planning.

[15] Najem, N. A. (2004). electronic management (strategic functions and problems).KSA: Dar almareekh.

[16] P. A. (2009). business management principles. Saudi Arabia: Public Institution for Technical Education and Vocational Training.
[17] Rezqallah, A. N. (2000). Organizational behavior (theory and practice). Egypt: Dar Engineering Press.

[18] Salmi, A. A. (2008). Electronic Management. Amman: Dar.

[19] Seresht, H. R., Fayyazi, M., \& Asl, N. S. (2008). Emanagement: Barriers and challenges in Iran. E-ower Kraklead , 1-11.

[20] Shilpa. (2010). Presentation Report. Punjab College Of Technical Education, Baddowal (Ludhiana).

[21] Yao et al., (2011). E-management development and deployment strategy for future organization. African Journal of Business Management, 6657-6667.

\section{AUTHOR'S PROFILE}

\section{Hanan Abdelhalim Rizk}

H. A. Rizk, A professor in Department of Educational and Psychological Sciences at faculty of Specific Education, Mansoura University, Mansoura, Egypt. She got her master and $\mathrm{PhD}$. degrees from faculty of Specific Education, Mansoura University.

\section{Ahmed El- Said Amin}

A. E. Amin, Associate professor in computer science at faculty of Specific Education, MansouraUniversity, Mansoura, Egypt. He got his master and PhD. degrees from faculty of Specific Education, MansouraUniversity.

Scientific areas of his interest include: Information System, Electronic learning, Mobile learning, Mobile agent.

a_e_amin@yahoo.com

\section{Maha Darweesh Elmorshedy}

M. D. Elmorshedy, professional developer . She got her diploma in software engineering at ITI Institute and She got another diploma in computer science at faculty of Specific Education, Mansoura University, Mansoura, Egypt.

Scientific areas of her interest include: Information System, Cloud Computing, Mobile learning, android, php, mysql. mahadarweesh66@gmail.com 